\title{
'I've Never Been So Exploited': The consequences of FOSTA-SESTA in Aotearoa New Zealand ${ }^{1}$
}

\author{
Erin Tichenor
}

\section{Abstract}

Aotearoa New Zealand's 2003 decriminalisation of sex work has reduced the exploitation of sex workers, as well as the health and safety risks in the industry. Nevertheless, United States-driven criminalising policies still influence sex workers abroad. The Fight Online Sex Trafficking and Stop Enabling Sex Traffickers Acts (FOSTA-SESTA) effectively criminalised websites where sex workers advertise. Shortly before that, the FBI shut down the internationally used Backpage.com, leading many sex workers in both countries to return to the streets or brothels. These events contributed to the rising dominance of one advertising website. Drawing on twenty semi-structured interviews and four observation cases with sex workers in Auckland, in this paper, I explore the international consequences of FOSTA-SESTA and the closure of Backpage on my participants. I show that this punitive approach to segments of the online sex industry has not only placed sex workers in greater financial insecurity, but has reduced their ability to control their working conditions. These outcomes, I conclude, have undermined the positive impacts of decriminalisation, while exacerbating socioeconomic, racial, gender, and legal inequalities in Auckland's sex industry.

Keywords: advertising, decriminalisation, trafficking, technology, New Zealand, United States, FOSTA-SESTA

Please cite this article as: E Tichenor, "I've Never Been So Exploited": The consequences of FOSTA-SESTA in Aotearoa New Zealand', Anti-Trafficking Review, issue 14, 2020, pp. 99-115, https://doi.org/10.14197/atr.201220147

1 This article has been modified after publication at the request of the author.

This is an open-access article distributed under the terms of the Creative Commons Attribution License (CC-BY). Under the CC-BY license, the public is free to share, adapt, and make commercial use of the work. Users must always give proper attribution to the authors and the Anti-Trafficking Review. 


\section{Introduction}

In Aotearoa New Zealand, ${ }^{2}$ citizen-resident sex workers have greater access to justice and labour rights due to the Prostitution Reform Act's (PRA) 2003 decriminalisation of sex work, accomplished by the activism of the New Zealand Prostitutes' Collective (NZPC). ${ }^{3}$ The number of sex workers in Aotearoa New Zealand has not changed significantly since decriminalisation, and there is no evidence of trafficking; in fact, the legal recourse granted to sex workers in the country has improved their ability to combat exploitation, violence, and health risks without facing the threat of a soliciting offence. ${ }^{4}$ In 2006, Abel et al. surveyed 772 sex workers across five cities, gleaning significant insight into the realities of the sex industry. About one-third of participants had tertiary degrees, and most were involved in other activities like volunteering, caregiving, or jobs outside of sex work. ${ }^{5}$ Although decriminalisation has reduced the disproportionate incarceration of transgender Māori street workers, who were frequently targeted by police raids but are now more able to work indoors, the street sector still has a much higher percentage of Māori, Pacific Islander, transgender, and/or people who began sex working before turning eighteen. ${ }^{6}$

In Auckland, about 57 per cent of the 1,513 estimated sex workers were working in 76 brothels or parlours, 23 per cent privately indoors, and 7 per cent on the

2 Aotearoa New Zealand has adopted the stance of biculturalism, combining the te reo Māori name, Aotearoa, with New Zealand, established later during British colonisation.

3 Since 1987, NZPC has been providing a wide array of support services for sex workers, ranging from condom distribution to legal aid. NZPC also works with the police, the Human Rights Commission, the City Council, and a plethora of other state and non-state bodies to promote sex workers' rights and reduce violence.

4 Sex work remains illegal for migrants, even those who have legal status and can work in other industries, under the provisions of Section 19 of PRA. G Abel, L Fitzgerald and C Brunton, The Impact of the Prostitution Reform Act on the Health and Safety Practices of Sex Workers, Report to the Prostitution Law Review Committee, Wellington, New Zealand, 2007, pp. 13, 16; G Abel, L Fitzgerald, C Healy, and A Taylor, Taking the Crime out of Sex Work: New Zealand sex workers' fight for decriminalisation, The Policy Press, Bristol, 2010.

5 Abel, Fitzgerald, and Brunton, 2007; G Abel, L Fitzgerald, and C Brunton, 'The Impact of Decriminalisation on the Number of Sex Workers in New Zealand', Journal of Social Policy, vol. 8, no. 3, 2009, pp. 515-531, https://doi.org/10.1017/ S0047279409003080; L Armstrong, 'New Zealand', in Global Alliance Against Traffic in Women, Sex Workers Organising for Change: Self-representation, community mobilisation and working conditions, GAATW, Bangkok, 2018, p. 95.

6 C Healy, A Wi-Hongi, and C Hati, 'Reflection from the Field. It's Work, It's Working: The integration of sex workers and sex work in Aotearoa/New Zealand', Women's Studies Journal, vol. 31, no. 2, 2017, p. 51. 
street. The indoor managed and private sector sex workers are older in age, and many are able to save money-often towards higher education. Street workers are more likely to be working because of an inability to receive a government benefit or parental support, because they have no other income, or to support a drug or alcohol habit. The vast majority of respondents had access to a doctor and felt able to refuse clients, though street workers more often experienced theft and threats of violence; managed workers were more likely to be punished if they refused to see a client. ${ }^{7}$

Internationally, the online expansion of the sex industry has overwhelmingly improved conditions for sex workers even in criminalised environments, by enabling more to work independently and communicate with peers about safety. ${ }^{8}$ However, US anti-trafficking policies that conflate consensual sex work with trafficking influence other nations' sex work laws, encouraging the criminalisation of migrant and street-based sex workers, clients, and most recently, their online platforms. ${ }^{9}$ The 2018 Fight Online Sex Trafficking and Stop Enabling Sex Traffickers Acts (FOSTA-SESTA) and the FBI's closure of the advertising site Backpage.com, affected sex workers who legally advertise online in Aotearoa New Zealand. ${ }^{10}$

In this article, I explore the material and emotional consequences of the loss of free US-based sites like Backpage.com for twenty-four sex workers in Auckland, posing questions about the wide reach of US anti-trafficking laws and the efficacy of punitive interventions that use technology to crosscut political borders. I argue that NZPC's model of sex worker-led advocacy and legislative guidance could be extended to advertising, where strategies of community empowerment and harm reduction could ensure that sex work advertised online is consensual, safe, and equitable.

Abel, Fitzgerald, and Brunton, pp. 72, 77, 80, 113, 116, 143.

8 B MacDonald, 'How the FBI has Disrupted NZ's Sex Work Industry', Radio New Zealand, 2018, retrieved 7 May 2019, https://www.rnz.co.nz/news/the-wireless/375230/how-the-fbi-has-disrupted-the-nz-sex-work-industry; L Chamberlain, 'FOSTA: A hostile law with a human cost', Fordham Law Review, vol. 87, issue 5, 2019, pp. 2171-2211; C Jackson and J Heineman, 'Repeal FOSTA and Decriminalise Sex Work', Contexts, vol. 17, issue 3, 2018, pp. 74-75, https://doi. org/10.1177/1536504218792534.

$9 \quad$ P Mahdavi and C Sargent, 'Questioning the Discursive Construction of Trafficking and Forced Labor in the United Arab Emirates', Journal of Middle East Women's Studies, vol. 7, no. 3, 2011, pp. 6-35, https://doi.org/10.2979/jmiddeastwomstud.7.3.6; A Tierney, 'The Effects of the Trump-signed SESTA/FOSTA are much more far-reaching than you would expect', Vice, 12 April 2018, https://www.vice.com/en_us/article/9kggwe/how-the-us-sex-trafficking-crackdown-is-hurting-sex-workers-in-canada; E Bernstein, Temporarily Yours: Intimacy, authenticity, and the commerce of sex, University of Chicago Press, Chicago, 2007.

$10 \quad$ MacDonald, 2018. 


\section{FOSTA-SESTA in Aotearoa New Zealand}

FOSTA-SESTA established a criminal liability for websites that operate a 'facility or means of interstate or foreign commerce ... with the intent to promote or facilitate the prostitution of another person', leading many websites like Instagram and Tumblr to remove all adult content to avoid prosecution. ${ }^{11}$ Prior to the enactment of FOSTA-SESTA, the FBI seized Backpage.com, a free advertising site used internationally by sex workers and their clients. ${ }^{12}$ Backpage's executives were charged on 93 counts, including money laundering and facilitating prostitution. ${ }^{13}$ However, the closure of Backpage and the removal of several adult content platforms remains controversial among sex workers and their advocates; suppressing an entire platform pushes sex workers to the streets or exploitative managers, where there is a higher risk of violence. ${ }^{14}$ Within one month of FOSTASESTA's passage, thirteen sex workers were reported missing, and two had committed suicide. ${ }^{15}$ The law also placed many independent online workers at risk of exposure to law enforcement due to technology companies' use of facial recognition and other tools for taking punitive anti-trafficking measures aiming to abolish prostitution. ${ }^{16}$

Cracker.com, a subsidiary of Backpage, remained live for a few days in Aotearoa New Zealand, before the FBI seized it as well. Website1 has been another popular site for years, and now dominates 90 per cent of the industry. Website1 has an exclusivity clause, which bars sex workers from advertising on other websites. Nevertheless, some sex workers at NZPC advertise on Website1, while others use sites like Website2, Website3, and the New Zealand Herald classified section. Sex worker-run sites like Website3 worked avidly to support sex workers affected by Backpage's closure, but Website1 still proved to be the most reliable source of clientele for many sex workers - at least in the first few months following FOSTASESTA.

11 Chamberlain, p. 2174; A Romano, 'A new law intended to curb sex trafficking threatens the future of the internet as we know it', Vox, 2 July 2018, https://www.vox.com/ culture/2018/4/13/17172762/fosta-sesta-backpage-230-internet-freedom.

12 Tierney, 2018.

13 D Oberhaus, 'The FBI just seized Backpage.com', Vice, 7 April 2018, https://www. vice.com/en_us/article/j5avp3/fbi-seized-backpage-sex-trafficking.

14 Chamberlain, p. 2172; Mitchell, 2018; MacDonald, 2018; E Taylor, 'Sex Workers are at the Forefront of the Fight Against Mass Surveillance and Big Tech', Observer, 12 November 2019, https://observer.com/2019/11/sex-workers-mass-surveillance-bigtech.

15 Chamberlain, p. 2174.

16 Taylor, 2019. 


\section{Trafficking Policy and Transnational Inequalities}

A large body of research has discussed how the social and economic positionality of sex workers, and the criminalisation and stigmatisation of sex work, rather than sex work itself, affects people's vulnerability to violence and exploitation. ${ }^{17}$ Elizabeth Bernstein has argued that varying legal regimes have little impact on socially patterned outcomes in the sex industry resulting from broader macroeconomic inequalities, 'whether sex work is decriminalised, legalized, or criminalised', migrant workers, sex workers of colour, street-based, and transgender sex workers still face greater discrimination, economic insecurity, and exposure to violence across multiple legal contexts. ${ }^{18}$ In Aotearoa New Zealand, the rollback of social welfare programmes and racial discrimination maintain underlying inequalities in the sex industry. ${ }^{19}$ For example, the racialised policing of Asian migrant sex workers often leads to their deportation, and encourages operators to take advantage of their illegal working status under the guise of 'protection' from law enforcement. ${ }^{20}$

While Bernstein compares outcomes between individual nations and their social structures, other feminist sociologists argue that persistent social and economic inequalities are products of global corporate and state power

17 L Agustin, Sex at the Margins: Migration, labour markets and the rescue industry, Zed Books, London, 2006; J Hagen, 'Compounding Risk for Sex Workers in the United States: Latinx queer and trans women will suffer disproportionally from a set of new laws restricting sex workers from seeking clients online', NACLA Report on the Americas, vol. 50, no. 4, 2018, p. 395-397, https://doi.org/10.1080/10714839.2018.155 0984; J Ham, Sex Work, Immigration, and Social Difference, Routledge, New York, 2017.

18 Bernstein, p. 164. See also: L Armstrong, 'Decriminalisation and the Rights of Migrant Sex Workers in Aotearoa/New Zealand: Making a case for change', Women's Studies Journal, vol. 31, no. 2, 2017, pp. 69-76; L Armstrong, 'Stigma, Decriminalisation, and Violence Against Street-Based Sex Workers: Changing the narrative', Sexualities, vol. 22, issue 7-8, 2019, pp. 1288-1308, https://doi.org/10.1177/1363460718780216; T Lyons et al., 'The Impact of Construction and Gentrification on an Outdoor Trans Sex Work Environment: Violence, displacement, and policing', Sexualities, vol. 20, no. 8, 2017, pp. 881-903, https://doi.org/10.1177/1363460716676990; D Ting, 'Understanding the Experiences of Migrant Asian Sex Workers in New Zealand: An exploratory study', Master's Thesis, Faculty of Sociology, University of Auckland, New Zealand, 2018, p. 113.

19 L Tan, 'Immigration NZ Admits Sex Industry Investigation Targets "Particular Nationality Groups", New Zealand Herald, 9 September 2018, https://www.nzherald. co.nz/nz/news/article.cfm?c_id=1\&objectid=12120192. See also: L Humpage, Policy Change, Public Attitudes and Social Citizenship: Does neoliberalism matter?, The Policy Press, Bristol, 2015.

20 Armstrong, 'New Zealand'; Ting, 2018, p. 88. 
relations that extend beyond 'naturalized geopolitical boundaries' ${ }^{21}$ In line with this logic, the wide scope of US anti-trafficking laws exposes the transnational effects of criminalisation in countries like Aotearoa New Zealand. The US Department of State's annual Trafficking in Persons Report (TIP Report) ranks countries based on their compliance with the 2000 Trafficking Victims Protection Act (TVPA) and states that 'prostitution and related activities encourage growth of modern day slavery by providing a facade behind which traffickers for sexual exploitation operate'.22 The TVPA and TIP Report encourage countries to focus on abolishing sex work through criminalisation, rather than prevent trafficking with equitable labour and migration policies. ${ }^{23}$ In Aotearoa New Zealand, scholars have argued that the TIP Report's abolitionist stance has driven border profiling and deportation of mostly Asian migrant sex workers. ${ }^{24}$ Notably, the New Zealand government is considering revising Section 19 to reduce its negative impact on migrant women. ${ }^{25}$

${ }^{21}$ H Kim-Puri, p. 139; see also: N Sharma, 'Anti-Trafficking Rhetoric and the Making of a Global Apartheid', NWSA Journal, vol. 17, no. 3, 2005, pp. 88-111.

22 United States Department of State, Trafficking in Persons Report, Washington, D.C., 2017; see also: J L Musto, 'What's in a Name? Conflations and contradictions in contemporary US discourses of human trafficking', Women's Studies International Forum, vol. 32, no. 4, 2009, pp. 281-287, https://doi.org/10.1016/j.wsif.2009.05.016; W Chapkis, 'Soft Glove, Punishing Fist: The Trafficking Victims Protection Act of 2000', in E Bernstein and L Schaffner (eds.), Regulating Sex: The politics of intimacy and identity, Routledge, New York, pp. 51-66.

23 J Chuang, 'The United States as Global Sheriff: Using unilateral sanctions to combat human trafficking', Michigan Journal of International Law, vol. 27, no. 2, 2006, pp. 437-494; G Soderlund, 'Running from the Rescuers: New US crusades against sex trafficking and the rhetoric of abolition', NWSA Journal, vol. 17, no. 3, 2005, pp. 64-87; E Bernstein, 'Militarized Humanitarianism Meets Carceral Feminism: The politics of sex, rights, and freedom in contemporary antitrafficking campaigns', Signs, vol. 36, no. 1, 2010, pp. 45-71, https://doi.org/10.1086/652918; Mahdavi, 'Questioning the Discursive Construction'; J Musto and d boyd, 'The Trafficking-Technology Nexus', Social Politics: International Studies in Gender, State \& Society, vol. 21, no. 3, 2014, pp. 461-483, https://doi.org/10.1093/sp/jxu018.

24 C Showden, 'From Human Rights to Law and Order: The changing relationship between trafficking and prostitution in Aotearoa/New Zealand policy discourse', Women's Studies Journal, vol. 31, no. 2, 2017, pp. 5-21. See also: Ting, 2018.

25 Committee on the Elimination of Discrimination against Women, Concluding observations on the eighth periodic report of New Zealand, 25 July 2018, https://undocs. org/CEDAW/C/NZL/CO/8, para. 28 (a); K Nicol-Williams, 'Calls for Foreigners to be able to Legally Operate in New Zealand's Sex Work Industry', TVNZ, 25 September 2018, https://www.tvnz.co.nz/one-news/new-zealand/calls-foreigners-able-legallyoperate-in-new-zealands-sex-work-industry. 
Technology accelerates these transnational policy convergences by drawing on growing 'collaboration between state, non-profit, and corporate actors.'. ${ }^{26}$ FOSTA-SESTA's policing of websites infiltrates settings well beyond its jurisdiction, like Aotearoa New Zealand's decriminalised and predominantly peer-regulated industry. ${ }^{27}$ Like the TIP Report, FOSTA-SESTA affects even sex workers supported by their local laws, because of the nearly borderless impact of online prohibitionist efforts. ${ }^{28}$ Advocates and scholars in the US have criticised FOSTA-SESTA for further criminalising sex workers, infringing upon their freedom of speech, and limiting law enforcement's tools for identifying victims of forced labour, all without targeting people who force others into sex work and hurt sex workers. ${ }^{29}$ Ben Chapman-Schmidt describes the way FOSTA-SESTA's anti-trafficking language silences sex workers' platforms for communication, advocacy, and security as 'epistemic violence' because of its exacerbation of risk in the whole industry. ${ }^{30}$

\section{Data and Methodology}

I studied abroad in Auckland during my third year of undergraduate studies in sociology and I interned at NZPC. Prior to arriving in Auckland, I had received approval from Boston University's Institutional Review Board to conduct ethnography, interviews, and focus groups, with NZPC's support. After beginning as an intern, I determined interviews to be the most appropriate method for the community.

I conducted two interviews with sex workers while I was an intern; the rest occurred after the internship ended. Snowball recruitment was particularly useful; two participants connected me with their private and managed peers who do not necessarily frequent NZPC.

Although my sample has limitations, including the lack of male sex workers, it does, to an extent, represent the diversity of Auckland's sex industry. All twentyfour participants were current sex workers affiliated with NZPC, and nearly

26 Musto and boyd, p. 465.

27 Tierney, 2018.

28 Mahdavi and Sargent, 2011; Musto and boyd, p. 464; Showden, 2017.

29 Chamberlain, p. 2209; B Chapman-Schmidt, “Sex Trafficking” as Epistemic Violence', Anti-Trafficking Review, issue 12, 2019, pp. 178-179, https://doi.org/10.14197/ atr.2012191211; Hagen, 2018; E Witt, 'After the Closure of Backpage, Increasingly Vulnerable Sex Workers Are Demanding Their Rights', The New Yorker, 8 June 2018, https://www.newyorker.com/news/dispatch/after-the-closure-of-backpage-increasingly-vulnerable-sex-workers-are-demanding-their-rights.

30 Chapman-Schmidt, p. 178. 
evenly distributed between the age groups of 20-29 ( $n=8), 30-39(n=9)$, and 40-50 ( $\mathrm{n}=7)$. I interviewed 19 cisgender and 5 transgender women. Participants' ethnicities were described as the following: Pākehā or White $(n=6)$, Māori $(n=2)$, Māori-Pākehā ( $\mathrm{n}=3)$, Asian ( $\mathrm{n}=7)$, Pacific Islander $(\mathrm{n}=2)$, African $(\mathrm{n}=2)$, and Other $(n=2) .{ }^{31}$ Seventeen participants were citizens $(n=15)$ or residents $(n=2)$ working legally, and seven were working illegally on the temporary tourist, student, and work visas. Four have always worked on the street, nine have always worked in managed brothels or parlours, and three have always worked privately. Eight have worked in multiple venues. The majority have been sex working for at least one year, but less than ten years $(n=16)$; four had only recently entered the industry when I interviewed them, and four had been working on and off for over twenty years. Two participants worked in Aotearoa New Zealand prior to decriminalisation, and nine have worked abroad in both decriminalised and criminalised settings.

For each interview, I described the broad research interest upon recruitment, and gave each participant time to read over and ask questions before providing written consent. Drawing from the internship, as well as previous research with NZPC, I created a semi-structured interview protocol to guide my questions. ${ }^{32}$ I followed a loose categorical guideline to address each participant's career history, experiences with law enforcement, advertising and/or managers, clients, the public, and peers. I had follow-ups about access to health services, use of NZPC, and experiences of discrimination. Interviews lasted between thirty minutes and two hours, and the majority took place in a private meeting room at NZPC. I interviewed two participants at their homes, one in a nearby coffee shop, and one over the phone, as per their requests. Participants were compensated NZD 40, based on discussions with NZPC about previous research with sex workers and the income potentially lost by interviewing rather than working for an hour. ${ }^{33}$

I audio recorded all but two interviews, and transcribed them by hand before conducting several rounds of coding using Nvivo Qualitative Analysis software. Topics like income, deportation, and sexual health comprised the major themes in my interview notes, and were reflected in the most referenced codes: 'money', 'business practices', 'health', 'migration', 'peers', and 'clients'. The three emergent themes were the ways in which race, gender, and legal status shaped participants' economic security, health outcomes, and criminalisation. Twenty-one participants voiced their frustrations with marketing, whether through online advertising sites, managers' practices, or other instances where they had little agency over advertising their services, gender, and ethnicity. This paper focuses on their marketing concerns

31 Categories have been slightly modified and condensed for the sake of confidentiality.

32 M Roguski, 'Occupational Health and Safety of Migrant Sex Workers in New Zealand', Kaitiaki Research and Evaluation, 2013; Ting, 2018.

33 All monetary values in the paper are in New Zealand Dollars (NZD). On 1 June 2018, USD 1 was equal to NZD 1.4319. 
and strategies within the context of FOSTA-SESTA. Each participant has been assigned a pseudonym, and all passages have been edited for clarity, but without changing the meaning of participants' responses.

\section{Findings}

The loss of advertising abilities on Backpage and other sites pushed many sex workers back to the streets or brothels, an immediate complaint voiced by many American sex workers ${ }^{34}$ and echoed by my participants. Those who remained independent confronted the challenging business practices of Website1, the dominant alternative to Backpage in Aotearoa New Zealand. Although Website3, Website2, and other sites tried to fill the Backpage void and protect sex workers' identities, they did not immediately provide enough clientele traffic compared to Website1, necessitating my participants' reliance on the streets, brothels, and Website1. Website1's high prices and surveillance practices compared to other sites are not new, but the scope of the discrepancy between sex workers' income and their ability to use a variety of websites amplified their financial distress. Second, these income constraints made some participants more likely to work with clients or provide services they would usually refuse. These constraints disproportionately affected transgender, migrant, and racial minority participants.

\section{The Material and Emotional Consequences of Income Insecurity}

The economic hardships following FOSTA-SESTA were related to participants' difficulty in finding clients, including the need to pay to access Website1 clientele. The day after Backpage shut down, workers visited NZPC, 'scrambling' for websites that would work with their unique services, but charge less than Website1's exorbitant fees. Irene (private, citizen, ciswoman, Asian) described the increasingly precarious nature of her work and the international reach of FOSTA-SESTA:

It's just made everything a lot more exploitative. I think people don't really look at what [FOSTA-SESTA]'s done here and go like 'holy fuck, what can it be doing in places that don't have'like we pretty much have the best decrim around if I'm not mistaken. But even here it's created an environment where people are having to crawl back to brothels.

34 T Mitchell, 'If Lawmakers Want to Protect Sex Workers, They Must Listen to Us', Huffpost, 8 March 2018, https://www.huffpost.com/entry/sex-workers-bill-fosta-sesta_n_5aa1924fe4b04c33cb6cecb2. 
Irene pointed out how a law, thousands of miles away, was hurting sex workers who have been relatively incorporated into New Zealand's mainstream workforce for sixteen years. Having heard about skyrocketing violence against sex workers in the US, she expressed sympathy for them, as well as fear that FOSTASESTA was having quasi-criminalising consequences in Auckland. Irene was acutely attuned to the symbolic consequences of this transnational policy flow, particularly when her clients discontinued bookings out of their own 'fear of the US police', or threatening her with 'the eyes of the US police'.

Most interview participants did not have another job like Irene did, and the immediate threat to their livelihood overpowered broader questions about the resurgence of criminalisation. Unfortunately, no one quite knew what was going to be the user-friendly, affordable 'new Backpage'. Sex workers coming to NZPC did not know 'where clients were going to flock to', and were stressed about having to spread their ads across multiple sites or to choose Website1. Knowing sex workers were struggling, Website1 raised their subscription prices from NZD 100 to 160 per week. Finding clients in Auckland meant paying more-even up to NZD 1000 per week for the perks of 'Diamond status'. Libby (private, citizen, ciswoman, African) explained how she failed to generate income if she did not pay the high rates for the Gold Tier: 'I always go with Gold, just because if you're not on those at least first two pages, then you don't get much work at all. There was one week where I slid to like third page. I think I got maybe like two clients that entire week.' Many participants still conceded to Website1's high fees since clients were flocking to it. Still, Irene and Olivia (private, citizen, ciswoman, Pacific Islander) had difficulty with Websitel's strict enforcement of their exclusivity clause when they tried to use different sites for different services or wanted to advertise elsewhere for a weekend. Olivia felt 'scared of going on another site for the weekend cause they'll punish you', and Website1 threatened to remove Irene from their site when she advertised different services elsewhere:
I had posted a Backpage ad-under a different name, with a different phone number, exclusively advertising [specific service]. Which is clearly a different service than I ever offer at a brothel, and they just identified me based on like race and body type and rang up the agency being like 'hey this breaches our non- competition rule'.

Unable to spread themselves over multiple sites, but reliant on Websitel's reach, participants found themselves spending more money on advertising or simply abandoning their independent work, at least until promising alternatives to Backpage emerged. Website1's privileging of 'mainstream' services (full service and girlfriend experience) particularly harmed niche and fetish workers' ability to work privately. Pepper (private and managed, citizen, ciswoman, Asian) said, 'Other sites are a lot less search engine friendly than Backpage was, which is why I'm having a lot of trouble connecting with clients. Private work has been 
real shit since Backpage shut down.' Pepper then explained how she has had to return to brothels because of the more reliable income and her manager's ability to pay the Website1 fees. Despite having to work hours that made balancing her university schedule and health condition difficult, her income relied on the business perks of Website1, like the ability to defend herself from a defamatory review. This rendered managed work Pepper's only immediate option.

Unlike Pepper's managers, others could not afford Website1's fees for businesses, pushing many to take more cuts from sex workers:

The way that you show that you're a good, ethical brothel owner was to advertise 'no fees' ... when I interviewed about a year ago, they didn't have any set shifts. They were real flexible with hours. No ad fees. A year later, they had set shifts, which are real rigid ... they increased the fee for not showing up from $\$ 30$ or working without ads to a straight up $\$ 55$ fee (Pepper).

The loss of Backpage did not only affect private sex workers who advertised online, but had reverberating consequences throughout the industry, placing hardship on managers and managed workers. Managers in Auckland, both burdened by rising prices and knowledgeable about many sex workers' desperation for work, moved to increasingly exploitative practices within their establishments. The next section discusses the consequences of this income precarity on participants' safety and choices at work.

\section{Consequences on Agency and Working Conditions}

Decriminalisation and the expansion of online advertising mitigated poor working conditions for sex workers, but FOSTA-SESTA has re-enabled these conditions, especially for low-income, racial and gender minorities, and migrant workers. Participants felt the need to change venues, accept clients they might otherwise avoid, provide extra services (e.g. anal sex), or enter unsafe situations because they could not afford to turn away clients. Some of the workers who could neither afford Websitel's rates nor to only see a few clients per week returned to the street or brothels, despite the amplified safety risks:

It hit my business pretty hard cause I don't have an advertisement hub anymore, so what I would get from doing jobs off [of Backpage] was about four or five times more than I do working on the street. And also, it was in a safe place. I would rent a room out at a brothel, and working on the street is mostly in people's cars and stuff like that, and you always get ripped off (Celia, street and private, citizen, transwoman, Pākehāa ${ }^{-35}$ ).

35 Pākehā is the Māori word for white or European New Zealander. 
Celia's need to work where she feels less safe and earns less money directly contradicts not only the aims of decriminalisation, but FOSTA-SESTA's stated goal to reduce coercion. Celia enjoys the ability to 'roam up and down' on the streets, and has excellent skills to prevent violence; however, this reduction in her choice over venue exposes the counterproductivity of criminalising efforts that attempt to abolish the sex industry.

FOSTA-SESTA also made private work less safe for New Zealanders who could afford to stay online. Independent participants were concerned about rising perceptions of sex workers' economic and legal precarity: 'why should we have to rely on pimps to make money when we could be working privately? It's so much more dangerous' (Irene). Previously, participants were able to screen clients on Backpage; being able to write their own advertisements and manage their own bookings helped them avoid people who would not respect their identity or services. After Backpage closed, many clients were 'clueless about where to turn', but others used the 'chaos' to test the boundaries of what services they could ask for:

\begin{abstract}
What struck me as soon as it happened, was that I was getting a lot more emails ... like 'now that Backpage is down, how about you become my live-in slave?' 'Now that Backpage is down, how about you get me to protect you?' 'Now that Backpage is down, I'm offering my screening services.' ... Conversely, a lot of fetish and fantasy friends started getting like the opposite. Like people who were into the most extreme shit, like 'I'm not paying you unless you drug me and kidnap me' (Irene).
\end{abstract}

Similarly, Website1's knowledge of its popularity and of sex workers' economic distress allowed them to control more of sex workers' marketing practices, which only heightened participants' concerns about loss of control over their working environment and safety: 'I cried! I was gutted that I had to go back to [Website1]. Just that feeling that somebody's like got their hand on top of your head' (Olivia). Olivia and Irene described how Website1 was 'making money left and right' by hiring new 'trolls', i.e. Websitel staff that search the internet for workers advertising elsewhere: 'your account manager spends much less time actually helping you and much more time trolling everywhere else on your ads and being like "you're not allowed to do this; you're not allowed to do that" (Irene). She added, 'Honestly, I've never been so exploited in my work by anyone, like by any agency, than I have been by [Website1]. And I think a lot of people would tell you the same thing-that they basically are a pimp.' Irene's reference to Websitel as a 'pimp' points to how punitive responses to trafficking actually result in more exploitative alternatives. Websitel enforced their 'hand on the top of your head' by making it harder for sex workers to control their hours and services - a norm that was prioritised by the PRA and NZPC's advocacy: 
To put your ad back on, you need to ring your account manager. So if you needed to put your ad up on Saturday, it won't be going back up until Monday until they open. So everything is governed by an account manager. Whereas Backpage, they made it easy-user-friendly. And you had complete control over it all (Olivia).

Website1 and other sites also make it harder for sex workers to 'go offline' when they were not working. Backpage allowed workers to pay a few dollars to boost their ads when they were working and remove them when they were not, but 'now you don't have a choice in the matter, so I'm not at all impressed. The others don't have the function to boost the ad when you're working. So if your ad is up at the top, it just stays at the top. So they all call you at three in the morning, two in the morning, I don't work those hours' (Joslyn, private, citizen, ciswoman, African).

These restrictions particularly harmed 'less mainstream' sex workers' businesses. Backpage allowed workers to thrive off of their unique skills and preferences, but Website1 is 'geared towards GFE [girlfriend experience] full service'-the most mainstream product. Pepper could attain sufficient business through focused advertisements for fetish, domination, and other niche services on Backpage, whereas remaining sites like Websitel prioritise sex workers' physical features like measurements and age. New platforms' focus on physical traits make it increasingly difficult for people to find clients and advertise their services in the manner they choose.

Joslyn summarised how websites' actions also reinforce racial hierarchies because other sites' marketing blurb constraints amplify the disconnect between who they are and what they are allowed to say to clients. For example, one site only has a space for nationality, but not ethnicity: 'they just need to give us a blank page. And then we can figure out what we like. [Website3] actually does have a space where you can put a paragraph, like natural, or extras. [Website1] on the other hand, they make the profile for you' (Joslyn). Websitel also requires expensive photographs: 'they would pick so many shots to put on your ad, and you don't actually get to pick the shots that they use. Which really pisses me off (Celia). Being able to decide their individual marketing strategies grants sex workers dignified work, but also reduces the risk of having to interact with violent, retaliatory, or otherwise problematic clients:

They tried to say 'you don't need to write your blurb! We know how to market Asian sex workers! You're going to drive away men with this content you've written!' And it's like 'shut the fuck up.' They nearly didn't let me put my own blurbs up. They kept trying to get me to Photoshop my photos, to lighten my skin, and so of course I'd have everyone be like 'oh you don't look like that!' (Irene) 
'Whitening' and photoshopping of photos contribute to Websitel's profit, but can lead to dangerous situations if clients describe online workers' skin tone or other characteristics as 'misleading' in their reviews. When managers advertise them as a different race or ethnicity over the phone or Websitel distorts their pictures, clients sometimes respond aggressively or demand refunds. Sex workers described how their independent advertisements would weed out discriminatory clients because 'they know what they are getting': 'with my pictures, you can see that I'm black. I guess if I worked in a more public place, then people would see me and maybe have something to say. Now, the person that's already coming to see me knows I'm black, so chances are they're comfortable with that' (Joslyn). Website1's constraints limit access to clients, disproportionately for racial and gender minorities, who more often have to combat stereotypes about beauty, deception, and submissiveness.

Similarly, transgender participants disclosed their gender identity as a safety precaution. The loss of a free website made Celia feel less safe and able to screen clients on the street:

About $90 \%$ of them don't realise that I'm trans, so there's always like a bit of a fear of what their reaction's gonna be. In the motels, it was like mostly people who were respectful ... And with the streets, they treat me like garbage really, some of them. There's the withholding money, just like trying to force you to do things (Celia).

Being upfront about being transgender is crucial online as well: 'on [another website], there's no column for transwomen. They've said that we can advertise in the female section. I make sure everyone knows I'm trans' (Esther, private, citizen, transwoman, Māori). Esther feels safer if she can advertise as a transwoman, while other women might face challenges choosing to advertise as female, even if they have undergone a vaginoplasty.

Finally, Website1's blatant segmentation of Asian and non-Asian sex workers facilitates racialised assumptions linked to migrant sex workers' illegality. There exist well-documented stereotypes about Asian sex workers, who Kimberly Hoang describes as being depicted either as beacons of 'modern cosmopolitan Asian ascendency' that are illegally working and 'taking natives' jobs', or as 'Third World victims in need of rescue'. Expectations of services, prices, and norms are based on these categorisations that are sought out by clients of differing backgrounds (i.e., Western backpackers, expatriates, elite businessmen, or middle-class locals). ${ }^{36}$ In Websitel's sector of the market, Pepper ridiculed

36 Hoang, 2015. 
how Asian migrant sex workers were discussed by clients as 'deceptive, rip offs, not worth the money, all the photos are fake, the ages are fake', and that 'you're not going to get the girl in the ad that you actually wanted'. When clients say, 'I went to this real cheap Asian place and got horribly ripped off and I got terrible service', other clients reply, 'well what did you expect?'

In contrast to this 'lucky-dip-possibly-get-a-real-bargain-possibly-get-rippedoff section, the 'non-Asian site is the reputable one'-a stereotype that Pepper believes the website creator intended to replicate. Website1's coded language such as 'here on tour', or 'exclusives for one week' hints at migrant sex workers' illegality, the consequences of which are compounded for Asian women who already face assumed illegality and scrutiny on the website. Some peers have taken advantage of these stereotypes, going so far as to call Immigration to report their online advertisements. ${ }^{37}$ The culture created by Websitel's categories and marketing language amplify Asian migrants' increased risk of exposure to Immigration, exploitation, and violence due to perceptions of them as 'deceptive' among peers, managers, and clients.

\section{Conclusion}

FOSTA-SESTA exemplifies the tensions between punitive anti-trafficking initiatives' stated goals to reduce harm in the sex industry, and the consequences of criminalisation that ultimately profit border security and tech corporations like Website1. Alongside the closure of Backpage, FOSTA-SESTA rendered New Zealander sex workers more vulnerable to exploitation and disempowerment because they had to turn to Website1, the streets, or managed workplaces for adequate income. Further, participants who were able to experiment with alternative websites, switch to well-run brothels, or who could reasonably afford Website1, were those advantaged by their race, age, gender, citizenship and/ or socioeconomic status. National policies like decriminalisation go a long way towards guaranteeing better conditions in the sex industry; however, the long punitive arm of the US is felt around the world, and disproportionately by marginalised populations.

Rather than resorting to laws that silence sex workers' expertise and dignity, efforts to address violence and coercion should prioritise social equity and community empowerment. NZPC, for example, provides a community space where sex workers can share health and safety information. In April 2018, many sex workers came into NZPC, informing each other about their experiences with

37 L Armstrong, 'New Zealand', p. 96; L Tan, 'NZ Sex Workers Lodge Complaints over Foreign Prostitute Website Advertisements', The New Zealand Herald, 22 April 2018, https://www.nzherald.co.nz/nz/news/article.cfm?c_id=1\&objectid=12037429. 
alternative sites that were more inclusive of a diversity of marketing practices. On street outreach, we learnt about how Website2 better accommodates transgender workers. NZPC National Coordinator Dame Catherine Healy has even suggested that despite this hardship, the industry could adapt to better accommodate independent workers into agencies, who would then provide more jobs for staff members. ${ }^{38}$ Dame Catherine's optimism about the industry's adaptability suggests that sex worker-led interventions across sectors are bestsuited for adapting to macroeconomic and policy changes that are out of their control.

Among the 772 respondents that Abel et al. surveyed, 65 per cent visited NZPC and 88 per cent received safety information from peers-staggering in comparison to the 10 per cent that did so from the police. Over 84 per cent of respondents in each sector learnt about their rights from NZPC and feel confident in them. ${ }^{39}$ NZPC's improvement of sex workers' well-being suggests that supporting more community-led efforts would help sex workers safely adapt to FOSTA-SESTA. For example, the New Zealand government could consult NZPC on policies relevant to sex workers and fund outreach and education about safe advertising practices. Further research should examine innovative post-FOSTA-SESTA advertising adaptations among peer sex workers in New Zealand.

Perhaps decriminalisation in Aotearoa New Zealand allows more room for peerbased solutions that prioritise sex workers' safety mechanisms, particularly due to their governmental support and the legality of alternatives to Backpage. Sex worker-led organisations who understand the realms of online advertising and online sex work (i.e. camming, pornography) are in the position to inform law enforcement and legislators on how to properly identify coercion online, without subjecting sex workers to surveillance, income insecurity, and more dangerous circumstances. Across legal settings, further attention should be given to peerbased technologies like online safety forums that have shown how technology is used to resist exploitation. ${ }^{40}$

More broadly, sex workers are in a knowledgeable insider position to assist one another. ${ }^{41}$ Sex workers have long been experts in preventing police harassment,

38 MacDonald, 2018.

39 Able, Fitzgerald and Brunton, p. 143.

40 Chapman-Schmidt, p. 185.

41 M Stacey and B Gerasimov, 'Introduction', in GAATW, 2018, pp. 5-41. See also: W Vollbehr, 'Sex Workers against Human Trafficking: Strategies and challenges of sex worker-led organisations in the fight against human trafficking', Master's Thesis, Vrije Universiteit Amsterdam, 2016. 
violence, and theft, yet nearly all anti-trafficking efforts have excluded them. ${ }^{42}$ Sex worker-led organisations should guide local interventions, inform legislation, and prevent harmful policies from emerging in the first place. Solutions may look different in specific contexts, but sex worker-led organisations are able to respond to local needs. For example, the Durbar Mahila Samanwaya Committee (DMSC) in West Bengal, India, not only addresses interstate trafficking, but implements peer health education, literacy programmes, and other supports for sex workers. Rather than 'dumping' trafficking victims and sex workers alike into state-run rehabilitation centres, DMSC has forged a working partnership with several agencies to ensure continuity of care, with a focus on the socioeconomic barriers to safe and consensual work. ${ }^{43}$

From Thailand to Canada and South Africa to Mexico, sex worker-led organisations pave a path for peer-based screening practices, and collaboration with multiple stakeholders in order to ensure sex workers' privacy and economic well-being, while assisting those who are forced into sex work. ${ }^{44}$ These community-based approaches to trafficking and exploitation prioritise harm reduction, social equity, empowerment, and dignity and they should be supported and replicated. Profit- and tech-motivated approaches organised around policing and surveillance will neither reduce harm nor promote justice, but will instead strengthen the carceral state's stronghold over people's bodies and work.

Erin Tichenor is a key worker for a transitional housing provider in Auckland, where she supports residents in establishing permanent housing and creating other support systems. She completed her B.A. in Sociology at Boston University, where she was a research assistant for the Departments of Sociology and Organizational Behavior. Her undergraduate honours thesis discussed how race, legal status, and gender moderate the benefits of New Zealand's 2003 decriminalisation of sex work due to the criminalisation of migrant sex workers and transnational laws like FOSTA-SESTA. Email: tichenor@bu.edu

42 Musto and boyd, p. 477.

43 S Jana et al., 'Combating Human Trafficking in the Sex Trade: Can sex workers do it better?', Journal of Public Health, vol. 36, issue 4, 2014, pp. 622-628, https://doi. org/10.1093/pubmed/fdt095; S Gayen, 'Innovative Approaches to Combat Trafficking of Women in the Sex Trade', Inter-Asia Cultural Studies, vol. 7, issue 2, 2006, pp. 331-337, https://doi.org/10.1080/14649370600674134.

44 M Stacey and B Gerasimov, 2018. 